\title{
CLINICAL AND HISTOPATHOLOGICAL EVALUATION OF EYELID LESIONS: RETROSPECTIVE ANALYSIS OF TERTIARY MEDICAL CENTER REFERRALS
}

\author{
Mustafa Ömer İzzettinoğlu ${ }^{1}$, Fatih Erkan Akay ${ }^{1}$ (D), Rüveyde Garip ${ }^{2}$ (D) \\ ${ }^{1}$ Trakya University School of Medicine, Edirne, TURKEY \\ ${ }^{2}$ Department of Ophthalmology, Trakya University School of Medicine, Edirne, TURKEY
}

\begin{abstract}
Aims: To clinically and histopathologically examine eyelid lesions and evaluate the consistency of clinical examination by comparing the provisional diagnoses of patients with their postoperative histopathology results. Methods: In this study, the records of 408 patients who applied to Trakya University, Department of Ophthalmology with an eyelid mass and underwent surgery between January 2000 to November 2019 were retrospectively analyzed. Patients' data comprised age, gender, location of the mass, lesion distribution according to age and gender, provisional clinical diagnosis of the patients, and histopathological reports. Results: Out of 408 patients, 220 (54\%) were female, and 188 (46\%) were male. The mean age of the patients was $46.9 \pm 20.17$ years (range; 5-90 years). In the histopathological examination of the lesions, $318(77.9 \%)$ of them were benign, and $90(22.1 \%)$ of them were malignant. The most common benign lesion was chalazion [112 (35.2\%)], while the most common malignant lesion was basal cell carcinoma [71 (78.9\%)]. The clinical pre-diagnosis and histopathological diagnosis were found to be compatible in $81(90 \%)$ patients with a malignant lesion. There was a statistically significant difference in age between malignant and benign lesions, where malignant lesions were found more in older patients. The histopathological examination ended up being malignant in $2.2 \%$ of the lesions with a benign provisional diagnosis. Conclusion: In conclusion, even though most common eyelid lesions in our study were found to be benign, some lesions diagnosed as benign in clinic were found to be malignant after histopathological examination. Hence all excisions should be evaluated histopathologically to achieve a better clinical outcome in all patients with an eyelid lesion. Keywords: Eyelid, lesion, basal cell carcinoma, chalazion
\end{abstract}

\section{INTRODUCTION}

Eyelid lesions are common to come across in ophthalmology clinics (1). These lesions can be congenital, inflammatory, traumatic, or neoplastic (benign or malignant) (2). Eyelid lesions can be various lesions of benign or malignant tumors generated from all cutaneous layers, except for the subcutaneous fat tissue alongside benign lesions referring to the majority percentage of all lesions $(2,3)$. Provisional diagnoses are made by clinical inspection using routine ophthalmologic practices and findings from the examination are verified by histopathological investigations (2). Inadequate and late diagnoses cause more risk for the patients and require more invasive surgeries, which usually end up with worse results $(4,5)$. Early diagnoses for malignant lesions especially happen to have high importance in the management of lesions through earlier treatment.

The incidence of eyelid lesions varies by genetic and environmental factors such as sunlight and ultraviolet radiation (6). Therefore, the distribution data of various lesions' locations are highly important for an ophthalmologist for the discrimination of the malignancies.

There are very few studies emphasizing the competence and importance of the provisional diagnoses approved with histopathological reports despite the existence of various studies evaluating demographical and histopathological features of eyelid lesions in our country. This study aims to evaluate the clinical, demographical, and histopathological features of eyelid lesions and the accuracy of provisional diagnoses and compare early diagnoses with histopathological reports.

\section{MATERIAL AND METHODS}

This study was approved by the Scientific Research Ethics Committee of Trakya University School of Medicine (Protocol Code: TÜTF-BAEK 2020/425). In this retrospective cross-sectional study, the data of 408 patients with an eyelid mass who were admitted to the tertiary ophthalmology clinic of Trakya University Hospital between January 2000 and November 2019 were evaluated retrospectively by histopathologically examining the materials of the patients that were obtained from mass excision. The study was carried out under the tenets of the Declaration of Helsinki. The written consent for the use of medical information of patients was also received from all of the participants or parents/guardians of the minors.

Demographic data such as patient's age and gender, location of the mass, lesion distribution according to age and gender, provisional clinical diagnosis of the patients, and histopathological reports were obtained from the medical records of the patients. 
Patients who were admitted to the ophthalmology department with the complaint of eyelid mass met the inclusion criteria. Patients with ophthalmological masses located in areas other than the eyelid were excluded from this study.

The collected data were analyzed statistically by using IBM SPSS version 20. Mean and standard deviation values were calculated using the descriptive statistical measures. The frequency distribution of qualitative data was quantified in numbers and percentages. The Chi-square test was used for qualitative comparison. Normality distribution of the data was evaluated with the One-sample Kolmogorov-Smirnov test. Quantitative data were compared with the Independent Sample t-Test. P-value of $<0.05$ was considered to be statistically significant.

\section{RESULTS}

In the present study, 220 (54\%) female, and 188 (46\%) male patients made up the total number of 408 patients. The mean age of the patients was $46.9 \pm 20.17$ years (range; from 5 to 90 years). Two hundred and twelve (51.9\%) patients had left eye involvement whereas 196 (48.1\%) patients had right eye involvement. The distribution of the lesions according to histopathological diagnoses, locations, and demographic features are presented in Table 1.

Ninety-five patients had a malignant provisional diagnosis, however, after histopathological analysis, only 81 of them were proved to have one. It was revealed that the detection rate with clinical examination was at $90 \%$. It was seen that $9(2.2 \%)$ out of

Table 1: Summary statistics for location, and demographic parameters of eyelid lesions according to benignancy and malignancy.

\begin{tabular}{|c|c|c|c|c|}
\hline & Benign Eyelid Lesions & Malignant Eyelid Lesions & Total & P-value \\
\hline Number of patients [n (\%)] & $318(77.9)$ & $90(22.1)$ & $408(100)$ & \\
\hline Gender [n (\%)] & & & & $<0.242$ \\
\hline Female & $178(55.9)$ & $43(47.8)$ & $221(100)$ & \\
\hline Male & $140(44.1)$ & $47(52.2)$ & $187(100)$ & \\
\hline $\operatorname{Age}^{*}$ & $41.67 \pm 18.74$ & $64.52 \pm 13.10$ & & 0.001 \\
\hline \multicolumn{5}{|l|}{ Location [n (\%)] } \\
\hline Upper eyelid & $181(56.9)$ & $22(24.4)$ & $203(50.7)$ & \\
\hline Lower eyelid & $110(34.6)$ & $48(53.3)$ & $158(38.7)$ & \\
\hline Medial epicanthus & $19(6)$ & $15(16.7)$ & $34(8.1)$ & \\
\hline Lateral epicanthus & $8(2.5)$ & $5(5.6)$ & $13(2.5)$ & \\
\hline
\end{tabular}

${ }^{*}$ Data were expressed as mean \pm standard deviation.

Statistically significant value is marked in bold.

Table 2: Summary statistics for histopathological diagnoses, location, and demographic parameters of benign eyelid lesions.

\begin{tabular}{|c|c|c|c|c|}
\hline Histopathological Diagnoses & Number of Patients [n (\%)] & Gender (Female/Male) & $A g e^{\star}$ & Location \\
\hline Chalazion & $114(27.94)$ & $59 / 53$ & $32.88 \pm 18.14$ & UE $58.0 \%$ \\
\hline Squamous papilloma & $43(10.54)$ & $21 / 22$ & $51.26 \pm 14.20$ & UE $58.1 \%$ \\
\hline Epidermal cyst & $28(6.86)$ & $15 / 13$ & $52.46 \pm 15.42$ & UE $53.8 \%$ \\
\hline Seborrheic keratosis & $22(5.39)$ & $9 / 13$ & $58.10 \pm 16.89$ & UE $45 \%$ \\
\hline Xanthelasma & $22(5.39)$ & $13 / 9$ & $45.33 \pm 6.71$ & UE $100 \%$ \\
\hline Cysts of Moll and Zeiss & $20(4.9)$ & $14 / 6$ & $39.94 \pm 4.88$ & LE $58.8 \%$ \\
\hline Nevus & $18(4.41)$ & $13 / 5$ & $46.75 \pm 7.84$ & UE $83.3 \%$ \\
\hline Verruca vulgaris & $14(3.43)$ & $9 / 5$ & $45.40 \pm 19.01$ & UE $80 \%$ \\
\hline Dermoid/epidermoid cyst & $12(2.94)$ & $2 / 10$ & $47 \pm 4.24$ & UE $83.3 \%$ \\
\hline Capillary hemangioma & $10(2.45)$ & $10 / 0$ & $39.40 \pm 24.35$ & $\mathrm{UE}=\mathrm{LE}$ \\
\hline Keratoacanthoma & $6(1.47)$ & $3 / 3$ & $51.67 \pm 15.67$ & LE $66.7 \%$ \\
\hline Cutaneous horn & $5(1.23)$ & $5 / 0$ & $37.20 \pm 12.73$ & UE $60.0 \%$ \\
\hline Xanthogranuloma & $2(0.49)$ & $1 / 1$ & $45 \pm 7.12$ & $\mathrm{UE}=\mathrm{LE}$ \\
\hline Trichoepithelioma & $2(0.49)$ & $1 / 1$ & $63 \pm 22.62$ & $\mathrm{UE}=\mathrm{LE}$ \\
\hline Apocrine hidrocystoma & $1(0.25)$ & $1 / 0$ & 50 & LEC \\
\hline
\end{tabular}

UE: Upper eyelid, LE: Lower eyelid, LEC: Lateral epicanthus

${ }^{*}$ Data were expressed as mean \pm standard deviation. 
Table 3: Summary statistics for histopathological diagnoses, location, and demographic parameters of malignant eyelid lesions.

\begin{tabular}{lccc} 
Histopathological Diagnoses & Number of Patients [n (\%)] & Gender (Female/Male) & Age \\
\hline Basal cell carcinoma & $71(17.40)$ & $35 / 36$ & $64.34 \pm 13.22$ \\
Squamous cell carcinoma & $14(3.43)$ & $4 / 10$ & $64.13 \pm 13.23$ \\
Sebaceous gland carcinoma & $3(0.74)$ & $2 / 1$ & $65 \pm 14.10$ \\
Malignant melanoma & $2(0.49)$ & $2 / 0$ & $74 \pm 2.82$ \\
\hline
\end{tabular}

LE: Lower eyelid, UE: Upper eyelid, MEC: Medical epicanthus

${ }^{*}$ Data were expressed as mean \pm standard deviation.

313 clinically benign lesions were histopathologically diagnosed as malignant lesions. 14 cases were suspected to be malignant lesions but histopathologically diagnosed as benign lesions. It was revealed that clinical pre-diagnosis of 304 (97.1\%) benign lesion cases was concordant with the histopathological reports. In addition, as for basal cell carcinoma (BCC) cases, it was seen that lower eyelid was the most common location yet there were 2 cases of BCC on lateral epicanthus (2.8\%). It was found that the correct clinical diagnosis rate of cases such as seborrheic keratosis, keratoacanthoma, and intradermal nevus was relatively low whereas the clinical diagnosis accuracy of cases such as chalazion, xanthelasma, squamous papilloma, Moll and Zeiss cysts were high. The distribution of the lesions according to histopathological diagnoses and the demographic features are presented in Tables 2 and 3.

\section{DISCUSSION}

Eyelid lesions are frequent occurrences in the daily practice of practitioners. Fortunately, even though some lesions may have findings of potential malignancy, they usually happen to be benign (2). Additionally, studies have revealed the incidence ratio of benign lesions ranges from $68.8 \%$ to $95 \%$ (4-9). In our study, this ratio was found to be $77.9 \%$, which is relatively lower compared to other studies that had larger sample sizes $(4,8)$. Alongside the differences in genetic and environmental factors, the difference in results could be attributed to cases that were pre-diagnosed with a malignant lesion who were then referred to a tertiary health care facility.

According to the literature, eyelid tumors are prone to be located on the lower eyelid followed by the upper eyelid, medial, and lateral epicanthus (8). Furthermore, it was indicated that the benign lesions are located more on the upper eyelid whereas malignant lesions are located more on the lower eyelid $(4,7,8)$. Our results were in line with the current literature. The reason for the number of malignant lesions being high on the lower eyelid is due to BCC being common in the population (5).

In our study, it was revealed that benign lesions occurred more commonly on female patients [178 (55.9\%)], and the malignant lesions on male patients [47 (52.2\%)]. A similar study by Coroi et al. (8), which was conducted with 471 cases, demonstrated that malignant lesions are more common in male patients. Moreover, the study of Huang et al. (4) supported the results of malignant lesions being more frequent on male patients with a ratio of $63.4 \%$. Additionally, the study revealed that the benign lesion features had no difference in location regarding gender (4). Malignant lesions are reported to occur at relatively older ages compared to benign lesions $(4,6,8,10)$. In our study, malignant lesions were found in patients of older ages, which is concordant with the literature.

In the present study, chalazion [114 (27.94\%)] was the most common benign lesion followed in order by squamous papilloma [43 (10.54\%)], epidermal cyst [28 (6.86\%)], seborrheic keratosis [22 (5.39\%)], and xanthelasma [22 (5.39\%)]. In a study that was conducted by Al-Faky (2), it was reported that the most common benign lesion was apocrine hidrocystoma, followed by chalazion, verruca, epidermal cyst, nevus, seborrheic keratosis, and xanthelasma. According to the study of Gundogan et al. (1), the five most common benign lesions were squamous papilloma, melanocytic nevus, seborrheic keratosis, epidermal cyst, and apocrine hidrocystoma. Chalazion was found as the most common benign lesion in the present study, whereas it was low in frequency in other studies. Diversity of the patient population who are admitted to health care centers, along with the difference in geography, could account for the dissimilarity in frequencies of eyelid lesions.

In previous studies, BCC was reported to be one of the most common malignant eyelid tumors $(4,6,8,10)$. On the other hand, according to studies conducted in Asia, squamous cell carcinoma (SCC) has a similar incidence as BCC, if not more common (1113). In studies that were based in Turkey, it was reported that BCC was the most common malignant tumor of eyelids, whereas SCC was the second most common $(1,5,7,9,14)$. BCC is mostly located in the lower eyelid (12). In the present study, BCC was mostly on the lower eyelid, and quite rarely lateral canthus, which is concordant with the basic knowledge of literature $(12,13)$. According to a study that was carried out in India by Kaliki et al. (13), 59\% of the SCC cases had an upper eyelid involvement. On the contrary, in our study, SCC was located in the upper and lower eyelids equally. It is postulated that SCC is located more in the upper eyelid due to the abundant meibomian glands the upper eyelid contains (10).

It was shown that $2.2 \%$ of the cases that were clinically pre-diagnosed with benign lesions turned out to have malignant lesions according to histopathological reports. In the study of Kersten et al. (15), this rate was reported to be at $1.9 \%$. In a study by Uzlu et al. (7), $4.7 \%$ of cases clinically pre-diagnosed with benign lesions were reported as premalignant, and $5.9 \%$ of cases were reported as malignant according to histopathological reports. In the present study, 3 cases that were evaluated as chalazion were later diagnosed as SCC after histopathological analyses. 2 malignant melanoma cases were evaluated as nevus. The high rate of inconsistency in incorrect diagnoses is considered to happen due to some lesions not taking place on a pre-diagnosis list because of their low occurrence; for instance, SCC could be confused with chronic blepharitis, especially at early stages. Keratoacanthoma and seborrheic keratosis are especially clinically evaluated as malignant lesions. Relatively less common eyelid lesions are significantly low in the accuracy of clinical diagnosis.

In the present study, demographic, and histopathological features of eyelid lesions in Turkey were evaluated. There are many studies regarding this topic in Turkey, and this study is a research article that evaluates the accuracy of recent clinical examinations. The most important limitation of this study was having a lower number of cases with rare eyelid lesions. Another limitation was that this study was conducted retrospectively. 
In conclusion, specialists could come across malignant lesions that can be evaluated as benign due to the fact that benign lesions of the eyelid are highly common. Therefore, the possibility of malignant lesions on patients who were pre-diagnosed clinically with benign tumors should be taken into account and detailed examination and histopathological investigations should be performed on the patients. Early diagnosis and surgical excisions of malignant lesions provide better management, save the patients from more complicated surgeries, and maintain more successful cosmetic results.

Ethics Committee Approval: This retrospective study was approved by the Scientific Research Ethics Committee of Trakya University School of Medicine (Protocol Code: TÜTF-BAEK 2020/425).

Informed Consent: Informed consent was obtained from all of the subjects. Conflict of Interest: The authors declared no conflict of interest.

Author Contributions: Concept: MÖİ, FEA, RG. Design: MÖİ, FEA, RG. Supervision: MÖİ, FEA, RG. Resources: MÖİ, FEA, RG. Materials: MÖİ, FEA, RG. Data collection and/or processing: MÖİ, FEA, RG. Analysis and/ or Interpretation: MÖİ, FEA, RG. Literature Search: MÖİ, FEA, RG. Writing Manuscript: MÖİ, FEA, RG. Critical Review: MÖİ, FEA, RG.

Financial Disclosure: The authors declared that this study received no financial support.

\section{REFERENCES}

1. Gundogan FC, Yolcu U, Tas A et al. Eyelid tumors: clinical data from an eye center in Ankara, Turkey. Asian Pac J Cancer Prev 2015;16(10):4265-9.

2. Al-Faky YH. Epidemiology of benign eyelid lesions in patients presenting to a teaching hospital. Saudi J Ophthalmol 2012;26(2):211-6.

3. Hussain I, Khan FM, Alam M et al. Clinicopathological analysis of malignant eyelid tumours in north-west Pakistan. J Pak Med Assoc 2013;63(1):25-7.
4. Huang YY, Liang WY, Tsai CC et al. Comparison of the clinical characteristics and outcome of benign and malignant eyelid tumors: an analysis of 4521 eyelid tumors in a tertiary medical center. Biomed Res Int 2015;2015:453091.

5. Karabulut HH, Karabulut YY, Şenel E et al. Göz kapağı tümörlerinin histopatolojik ve demografik özellikleri. Turk J Dermatol 2014;4:197-201.

6. Bagheri A, Tavakoli M, Kanaani A et al. Eyelid masses: a 10-year survey from a tertiary eye hospital in Tehran. Middle East Afr J Ophthalmol 2013;20(3):187-92.

7. Uzlu D, Akyol N, Ercin ME et al. Kliniğimizde cerrahi olarak tedavi edilen göz kapağı tümörlerinin histopatolojik bulguları. Dicle Tip Derg 2020;47:146-53.

8. Coroi MC, Roşca E, Muţiu G et al. Eyelid tumors: histopathological and clinical study performed in County Hospital of Oradea between 2000-2007. Rom J Morphol Embryol 2010;51(1):111-5.

9. Keçeci Y, Taşlı FA, Sır E et al. Göz kapağı tümörlerinin insidansı. Turk J Plast Surg 2013;21(2):20-3.

10. Ho M, Liu DTL, Chong KKL et al. Eyelid tumours and pseudotumours in Hong Kong: a ten-year experience. Hong Kong Med J 2013;19(2):150-5.

11. Kumar R. Clinicopathologic study of malignant eyelid tumours. Clin Exp Optom 2010;93(4):224-7.

12. Jahagirdar SS, Thakre TP, Kale SM et al. A clinicopathological study of eyelid malignancies from central India. Indian J Ophthalmol 2007;55(2):109-12.

13. Kaliki S, Bothra N, Bejjanki KM et al. Malignant eyelid tumors in India: a study of 536 Asian Indian patients. Ocul Oncol Pathol 2019;5:210-9.

14. Kurt A, Mutlu S, Yener $\mathrm{H}$ et al. Primer göz kapağı tümörlerinde histopatoloji sonuçları. Dicle Tip Derg 2015;42(1):72-7.

15. Kersten RC, Ewing-Chow D, Kulwin DR et al. Accuracy of clinical diagnosis of cutaneous eyelid lesions. Ophthalmology 1997;104(3):479-84 